\title{
Can vesicle size distributions assess eruption intensity during volcanic activity?
}

\author{
A. LaRue ${ }^{1}$, D. R. Baker ${ }^{1}$, M. Polacci ${ }^{2}$, P. Allard ${ }^{3}$, and N. Sodini ${ }^{4}$ \\ ${ }^{1}$ Department of Earth and Planetary Sciences, McGill University, Montréal, Québec, Canada \\ ${ }^{2}$ Istituto Nazionale di Geofisica e Vulcanologia, Sezione di Pisa, Pisa, Italy \\ ${ }^{3}$ Institut de Physique du Globe, Paris Sorbonne Cité, Paris, France \\ ${ }^{4}$ Elettra Sincrotrone Trieste, Basovizza, Trieste, Italy
}

Correspondence to: D. R. Baker (don.baker@mcgill.ca)

Received: 7 May 2013 - Published in Solid Earth Discuss.: 19 June 2013

Revised: 22 August 2013 - Accepted: 29 August 2013 - Published: 18 October 2013

\begin{abstract}
We studied three-dimensional (3-D) vesicle size distributions by X-ray microtomography in scoria collected during the relatively quiescent Phase II of the April-May 2010 eruption at Eyjafjallajökull volcano, Iceland. Our goal was to compare cumulative vesicle size distributions (VSDs) measured in these samples with those found in Stromboli volcano, Italy. Stromboli was chosen because its VSDs are well-characterized and show a correlation with eruption intensity: typical Strombolian activity produces VSDs with power-law exponents near 1, whereas larger and more energetic vulcanian-type explosions and Plinian eruptions produce VSDs with power-law exponents near 1.5. The first hypothesis to be tested was whether or not the samples studied in this work would contain VSDs similar to normal Strombolian products, display higher power-law exponents, or be described by exponential functions. Before making this comparison, we tested a second hypothesis, which was that the magma-water interactions in the Eyjafjallajökull eruption might have a significant effect on the VSDs. We performed 1 bar bubble-growth experiments in which the samples were inundated with water and compared them to similar control experiments without water inundation. No significant differences between the VSDs of the two sets of experiments were found, and the second hypothesis is not supported by the experimental evidence. The Phase II Eyjafjallajökull VSDs are described by power-law exponents of $\sim 0.8$, typical of normal Strombolian eruptions, and support the first hypothesis. The comparable VSDs and behavior of Phase II of the Eyjafjallajökull 2010 eruption to Stromboli are interpreted to be a reflection of similar conduit systems in both volcanoes
\end{abstract}

that are being constantly fed by the ascent of mingled/mixed magma from depth. Such behavior implies that continued activity during Phase II of the Eyjafjallajökull eruption could be expected and would have been predicted, had our VSDs been measured in real time during the eruption. However, the products studied show no peculiar feature that could herald the renewed eruption intensity observed in the following Phase III of the eruption.

\section{Introduction}

The April-May 2010 explosive eruption at Eyjafjallajökull volcano, Iceland $\left(63.63^{\circ} \mathrm{N}, 19.6215^{\circ} \mathrm{W} ; 1666 \mathrm{~m}\right.$ a.s.l. $)$, had billion-dollar consequences for the aviation industry during its early eruptive phase on 14-18 April (Thomas and Prata, 2011) and continues to influence flight procedures and rules in airspace contaminated by volcanic ash (ICAO, 2012). Extensive ice-magma interactions promoted fine ash generation during the first part of the eruption (Sigmundsson et al., 2010), and ash-laden volcanic plumes had significant consequences owing to both high column height and prevailing winds at the time (Thomas and Prata, 2011).

The 2010 eruption of Eyjafjallajökull can be divided into 4 distinct eruptive phases (Gudmundsson et al., 2012). Phase I marked the beginning of the eruption, 14 April to 18 April, and is subdivided into 2 stages: Stage 1 characterizes the first 15-17 hours of eruption during which magma broke the summit ice cap, creating ash-poor, vapor-rich volcanic plumes that rose up to $9 \mathrm{~km}$ into the atmosphere; Stage 2 began with 
the ejection of a dark, ash-rich plume and was typified until April 18 by pulsating explosive activity driven by magmatic and phreatomagmatic fragmentation. Phase II marked a decrease in explosive activity, column height and lava emission, but was characterized by intense volcanic tremor until 4 May; 28 April was an exceptional day during Phase II when the eruption column rose to $\sim 7 \mathrm{~km}$ height. Phase III, beginning on 5 May, followed a burst of deep $(\sim 20-25 \mathrm{~km})$ seismicity (Sigmundsson et al., 2010) and was typified by a gradual decrease in volcanic tremor but an initial increase in explosive activity driven by both magmatic and phreatomagmatic fragmentation, generating $5 \mathrm{~km}$ high ash-laden plumes. Phase IV, from 19 May to 9 June, showed a progressive decline in eruptive and seismic activity (Hoskuldsson et al., 2011).

Scoria samples collected from Phase II were analyzed using synchrotron X-ray 3-D microtomography ( $\mu-\mathrm{CT})$, and their vesicle size distributions (VSDs) were compared with those analyzed in natural scoriae from Stromboli volcano, Italy, on which extensive 3-D textural research has been conducted (e.g., Polacci et al., 2009). The goal of this study was to test the hypothesis that these samples could be used to assess if the behavior at the time of sample collection could be expected to continue and if any assessment could be made concerning future behavior, in particular the enhanced activity seen in Phase III of the eruption. Prior to this, Eyjafjallajökull products had to be investigated for the possible effects of magma-water interaction on VSDs through laboratory experiments in which hydrated melts were degassed at 1 bar while being inundated with water from an external source.

\section{Methods}

\subsection{Analysis of natural scoria}

Scoria samples of mostly lapilli size that erupted on 29 and 30 April during Phase II of the Eyjafjallajökull eruption were collected by one of us (M. P.) on 8 May 2010. The scoria samples completely covered the surface of the glacier and were taken directly from icy ground about $800 \mathrm{~m}$ west of the crater rim. Eight representative samples, selected after optical inspection, were analyzed using synchrotron $\mu$-CT at the SYRMEP beamline of the Elettra Synchrotron Light Source, Basovizza, Italy. Samples were mounted on a precision stage at a sample-to-detector distance of $20 \mathrm{~cm}$ and rotated $180^{\circ}$ around an axis perpendicular to the monochromatic X-ray beam, following Polacci et al. (2009). The configuration for each scan was a ring energy of $2.0 \mathrm{GeV}$ and an X-ray beam energy of 17 to $29 \mathrm{KeV}$. Projection images were recorded at $1 / 5$ degree rotation steps using a detector system consisting of a 12 bit water-cooled CCD camera coupled to a gadolinium oxysulfide scintillator by a straight fiber optic coupler. The CCD field of view was $18.0 \times 12.0 \mathrm{~mm}^{2}$, producing voxels with edge lengths of $9 \mu \mathrm{m}$. The resulting radiographs were reconstructed into tomographic projections via the Gridrec

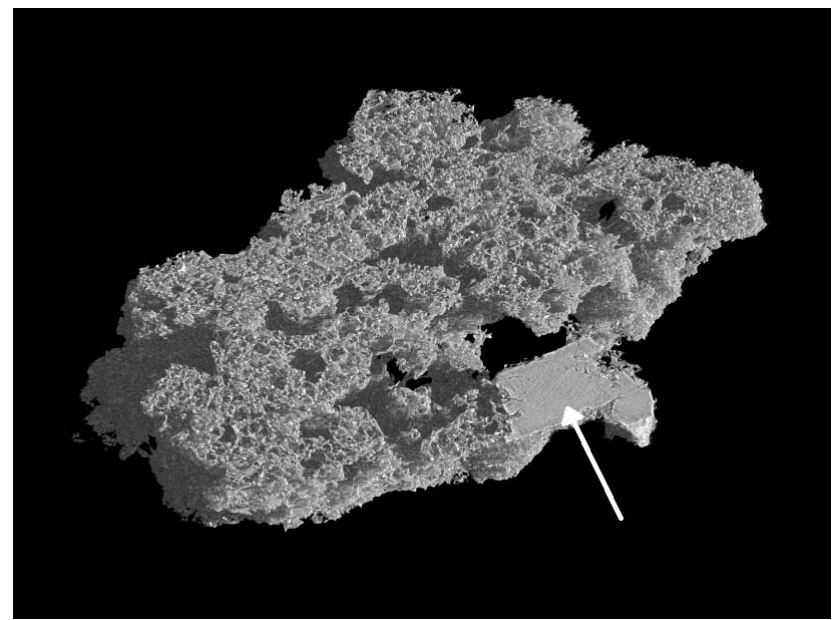

Fig. 1. Three-dimensional X-ray microtomographic rendering of natural sample EFJ080510b; a plagioclase crystal (indicated by the arrow), which is rare in products of this eruption that had less than $2 \%$ crystallinity (Sigmundsson et al., 2010), can clearly be seen in the sample. The long dimension of this sample is $1.06 \mathrm{~cm}$.

algorithm (Rivers, 1998) with the creation of 400 2-D image slices. These slices were used to produce 3-D volumes of the investigated samples (Fig. 1).

\subsection{Experimental analysis of magma-water interaction}

Hydrated glass was produced from the natural Eyjafjallajökull scoria for magma-water interaction (MWI) degassing experiments in which vesiculating melt at 1 bar was inundated with water to simulate the hydrous conditions present during the Eyjafjallajökull eruption. To synthesize the hydrated glass, platinum capsules were filled with powdered scoria and water, such that water concentrations dissolved in the melt would be between 1.7 and $4.1 \mathrm{wt} \%$. These water concentrations correspond to supersaturation pressures between 30 and $110 \mathrm{~Pa}$ when degassed at 1 atm (Baker and Alletti, 2012). The capsules were welded and stored overnight at $110^{\circ} \mathrm{C}$ to verify the weld. Capsules were then loaded into a $1.91 \mathrm{~cm}$ crushable alumina-pyrex assembly (Baker, 2004) and placed in the piston cylinder. Pressure was held at $1 \mathrm{GPa}$ and $1200^{\circ} \mathrm{C}$ for $1 \mathrm{~h}$ before isobaric quenching to produce crystal-free, hydrous glasses.

Chips of about $20 \mathrm{mg}$ in weight were selected from the hydrous glasses, rapidly melted in a 1 bar furnace and inundated with copious amounts of water. This experimental technique approximately simulates instantaneous decompression (see Bai et al., 2008, 2010) combined with magmawater interaction. These MWI experiments' only goal was to investigate vesicle growth and the evolution of vesicle sizes and distributions under conditions similar to those of near-surface degassing in a volcanic eruption. These experiments are useful for the study of the development and evolution of vesicle size distributions and thus complementary 
to classical, high-pressure, bubble nucleation and growth experiments (e.g., Hurwitz and Navon, 1994). The calculated water/rock ratio of the experiments is $\sim 1500$ based upon the masses of the melt and of the water injected into the furnace, but we do not know how much water is lost from the furnace before contacting the melt. Samples were heated at $\sim 100^{\circ} \mathrm{C} \mathrm{min}^{-1}$ to a maximum temperature ranging between $800^{\circ} \mathrm{C}$ and $1000^{\circ} \mathrm{C}$. However, the majority of samples were heated to $850^{\circ} \mathrm{C}$ and held at that temperature for $60 \mathrm{~s}$ before water was injected. Temperature decreased immediately upon contact with water, and the sample was removed from the furnace when temperature reached approximately $50{ }^{\circ} \mathrm{C}$.

Following the methods of Bai et al. (2008), another set of hydrated glass chips was heated at 1 bar to temperatures of $800^{\circ} \mathrm{C}$ to $1056^{\circ} \mathrm{C}$ on the GSECARS bending magnet beamline at the Advanced Photon Source synchrotron, Argonne National Laboratory, USA, without water inundation. These experiments (called hereafter control experiments) were monitored by X-ray radiography using a CCD camera that provides in situ observation of the experiment. During these control experiments, samples were heated until they produced vesicles, generally between $925^{\circ} \mathrm{C}$ and $1042^{\circ} \mathrm{C}$, and the melt was then quenched. All experimental run products were analyzed using synchrotron X-ray $\mu$-CT at the GSECARS beamline. The X-ray beam used for $\mu$-CT of the experiments had an energy of $15 \mathrm{keV}$ and a voxel edge length of $3.96 \mu \mathrm{mpixel}^{-1}$. Samples were mounted on a precision stage and rotated $180^{\circ}$ with $1 / 4$ degree increments around an axis perpendicular to the monochromatic $\mathrm{X}$-ray beam, producing 720 images (Bai et al., 2008). Transmitted X-rays were converted into visible light with a YAG phosphor screen that was imaged with a cooled CCD camera. Reconstruction of the 3-D tomographic images was done with the Gridrec algorithm as implemented in the IDL programming language (Rivers, 1998).

The 3-D tomographic volumes of both the natural scoria and experimental run products were processed using ImageJ (Abramoff et al., 2004) and Blob3D (Ketcham, 2005) software. A 3-D Gaussian filter in Blob3D was applied to the stacks in order to minimize background noise in the tomographic images before determining the number of vesicles and their sizes. The resulting data were then used to measure vesicle size distributions. Other details of the post-processing and analysis can be found in Bai et al. (2008) and Polacci et al. $(2009,2010)$.

\section{Results}

Scoria samples used in our study range from approximately 1 to $3 \mathrm{~cm}$ in length and have a trachyandesitic bulk composition (Sigmundsson et al., 2010) and groundmass of benmoreitic composition (Sigmarsson et al., 2011; Gudmundsson et al., 2012). Their vesicularity varies between $65 \%$ and $77 \%$, with an average of $72 \pm 4.5 \%$ (1 standard deviation) (Table 1).
Power-law relationships for cumulative vesicle size distributions are discernible in each scoria sample, and the exponents were calculated for vesicle volumes between approximately $10^{4}$ and $10^{5} \mu \mathrm{m}^{3}$ (Fig. 2, Supplement). Only a few vesicles with greater volumes were found in each sample; the maximum vesicle size was $\sim 10^{9} \mu \mathrm{m}^{3}$, or $1 \mathrm{~mm}^{3}$. The power-law exponents describing the VSDs in the scoria range between 0.57 and 0.96 , with an average of $0.76 \pm 0.12$ ( 1 standard deviation). Vesicle number densities (VNDs) were calculated for each sample; VNDs for natural samples are low, varying from 5.4 to 16.9 per $\mathrm{mm}^{3}$ (Fig. 2, Table 1).

The average vesicularity of the MWI experiments is $24 \pm 17.6 \%$. The vesicularities range from $6 \%$ to $55 \%$; this variability is due to small variations in bubble nucleation and growth, the duration of the experiments and to variations in the quenching efficiency of the water inundation. The MWI run products have VSD power-law exponents between 0.48 and 1.10, with an average of 0.72 and a standard deviation of 0.23 over the same vesicle volume range measured in the natural samples, $\sim 10^{4}$ to $10^{5} \mu \mathrm{m}^{3}$ (Table 1, Fig. 3, Supplement). In many samples the power-law region of the MWI run products extends over a vesicle volume range from $10^{3}$ to $10^{6} \mu \mathrm{m}^{3}$. The maximum vesicle size is commonly $\sim 10^{7} \mu \mathrm{m}^{3}$. Their VNDs vary between 667 and 7491 per $\mathrm{mm}^{3}$.

The vesicularity of experimental samples degassed without water inundation, the control experiments, averages $48 \pm 26.5 \%$. The vesicularities of the control experiments vary from $23 \%$ to $89 \%$. The variability is due to the stochastic nature of bubble nucleation and growth as well as small differences in the duration of the experiments designed to produce a range of vesicularities. The VSD power-law exponents of the control experiments are similar to those of the MWI experiments; they vary from 0.36 to 0.97 over the same volume range, with an average of 0.71 and a standard deviation of 0.23 . The VNDs of the control experiments range between 725 and 3896 per $\mathrm{mm}^{3}$. Importantly, we can discern no significant differences in VSDs and VNDs between the MWI and the control experiments. Furthermore, the experimental VSDs at high vesicularities are similar to those of the natural scoria (Figs. 2 and 3, Table 1, Supplement).

\section{Discussion}

\subsection{Does magma-water interaction affect the VSDs of volcanic products?}

The experiments conducted in this study demonstrate no significant difference between the power-law vesicle distributions for the MWI experiments and those of the control experiments without water inundation (Table 1). This lack of difference is attributed to the dominant control of VSDs by the exsolution of magmatic water from the melt. The water inundation during vesicle growth only appeared to quench 
Table 1. Summary of vesicle size distributions (VSDs), vesicularity, sample volume and vesicle number density (VND).

\begin{tabular}{|c|c|c|c|c|c|}
\hline Sample & Description & $\begin{array}{c}\text { Power- } \\
\text { law exponent }\end{array}$ & $\begin{array}{c}\text { Vesicularity } \\
(\%)\end{array}$ & $\begin{array}{c}\text { Sample } \\
\text { volume }\left(\mathrm{mm}^{3}\right)\end{array}$ & $\begin{array}{c}\text { VND } \\
\left(\text { permm }^{3}\right)\end{array}$ \\
\hline EFJ050810B_e & Natural scoria & 0.74 & 66.7 & 94.1 & 10.4 \\
\hline EFJ050810b & Natural scoria & 0.96 & 72.2 & 14.8 & 11.3 \\
\hline EFJ080510B_b & Natural scoria & 0.76 & 65.5 & 27.0 & 17.0 \\
\hline EFJ080510B_c & Natural scoria & 0.57 & 77.6 & 35.7 & 5.4 \\
\hline EFJ080510B_f & Natural scoria & 0.81 & 71.8 & 21.9 & 6.9 \\
\hline EFJ080510B_g & Natural scoria & 0.81 & 72.3 & 25.1 & 14.6 \\
\hline EFJ080510B_h & Natural scoria & 0.66 & 76.3 & 18.1 & 8.9 \\
\hline EFJ_7a & $\mathrm{MWI}^{\mathrm{a}}, 2.0$ wt. $\% \mathrm{H}_{2} \mathrm{O}^{\mathrm{b}}$ & 0.48 & 5.5 & 0.2 & 667.1 \\
\hline EFJ_5a & MWI, 3.2 wt. $\% \mathrm{H}_{2} \mathrm{O}$ & 0.59 & 10.7 & 0.2 & 799.0 \\
\hline EFJ_6b & MWI, 4.1 wt. $\% \mathrm{H}_{2} \mathrm{O}$ & 0.86 & 18.3 & 0.1 & 2725.1 \\
\hline EFJ_7b & MWI, 2.0 wt. $\% \mathrm{H}_{2} \mathrm{O}$ & 1.10 & 23.0 & 0.4 & 7491.6 \\
\hline EFJ_5c & Control $^{\mathrm{c}}, 3.2$ wt. $\% \mathrm{H}_{2} \mathrm{O}$ & 0.80 & 23.4 & 0.6 & 3371.2 \\
\hline EFJ_2e & Control, 1.7 wt. $\% \mathrm{H}_{2} \mathrm{O}$ & 0.81 & 24.0 & 0.4 & 3895.5 \\
\hline EFJ_7d & Control, 2.0 wt. $\% \mathrm{H}_{2} \mathrm{O}$ & 0.36 & 25.3 & 0.4 & 724.8 \\
\hline EFJ_6d & MWI, 4.1 wt. $\% \mathrm{H}_{2} \mathrm{O}$ & 0.59 & 31.6 & 0.1 & 2636.9 \\
\hline EFJ_7c & MWI, 2.0 wt. $\% \mathrm{H}_{2} \mathrm{O}$ & 0.70 & 54.5 & 0.2 & 1649.4 \\
\hline EFJ_7e & Control, 2.0 wt. $\% \mathrm{H}_{2} \mathrm{O}$ & 0.51 & 56.2 & 0.7 & 766.1 \\
\hline EFJ_10d & Control, 2.7 wt. $\% \mathrm{H}_{2} \mathrm{O}$ & 0.79 & 57.8 & 0.5 & 1246.4 \\
\hline EFJ_10b & Control/McGill ${ }^{\mathrm{d}}, 2.7$ wt. $\% \mathrm{H}_{2} \mathrm{O}$ & 0.97 & 88.8 & 0.1 & 2793.8 \\
\hline
\end{tabular}

the experiment rapidly and most probably only interacted chemically with the outermost few microns of the samples. Such rapid quenching would be expected in nature at the interface between magma and a water-saturated medium when the system is dominated by water (as in these experiments). The VNDs of the experimental samples with and without water inundation are remarkably similar and quite high, in the thousands per cubic mm (Table 1), indicating that vesicle nucleation occurs rapidly, even in the MWI experiments that were rapidly quenched. These results suggest that magmawater interaction does not significantly affect the VSDs and their power-law exponents for the majority of volcanic ejecta produced during the eruption. However, we cannot entirely eliminate the possibility that Eyjafjallajökull ejecta formed in very close proximity to the magma-water interface may be affected because the corresponding region of our experiments was too small to resolve spatially.

Although extrapolating the VSDs of experiments such as those in this work with dimensions of millimeters to the size of natural scoria samples with dimensions of centimeters, or greater, represents a challenge in volcanology, it has been shown successful in a number of previous studies. In particular, the VSDs of experiments performed on K-rich basaltic scoria products from Stromboli (Bai et al., 2008, 2010, 2011), using the same techniques as in this study, demonstrated close correspondence to measurements made on natural scoria and pumice samples from this same volcano (Polacci et al., 2008, 2009).

\subsection{VSDs and volcanic eruption intensity}

Since the pioneering studies of Cashman and Mangan (1994) and Mangan and Cashman (1996), many investigations have measured the vesicle size distributions in volcanic ejecta and lavas (e.g., Gaonac'h et al., 1996, Sable et al., 2006; Lautze and Houghton, 2007; Andronico et al., 2008; Costantini et al., 2010). Although early studies measured VSDs only in two dimensions, 3-D measurements, which are the only way to measure accurately the VSDs of complex vesicle shapes, recently have become common (Baker et al., 2012, and references therein). Currently, the VSDs of volcanic products from Stromboli, Italy, are amongst the samples best studied in 3-D. Stromboli is famous for two differing eruption styles: the daily, low-intensity Strombolian activity with explosion heights of tens to a few hundreds of meters and small total ejecta volumes (Bertagnini et al., 1999); and more powerful paroxysmal explosions reaching up to $\sim 4 \mathrm{~km}$ height and ejecting meter-sized ballistic blocks (e.g., Métrich et al., 2005) that occur one to three times per year and are powered by deeper-derived, $\mathrm{CO}_{2}$-rich gas (Allard, 2010). Three-dimensional studies of respective ejecta have shown that normal Strombolian activity produces scoria with VSD 

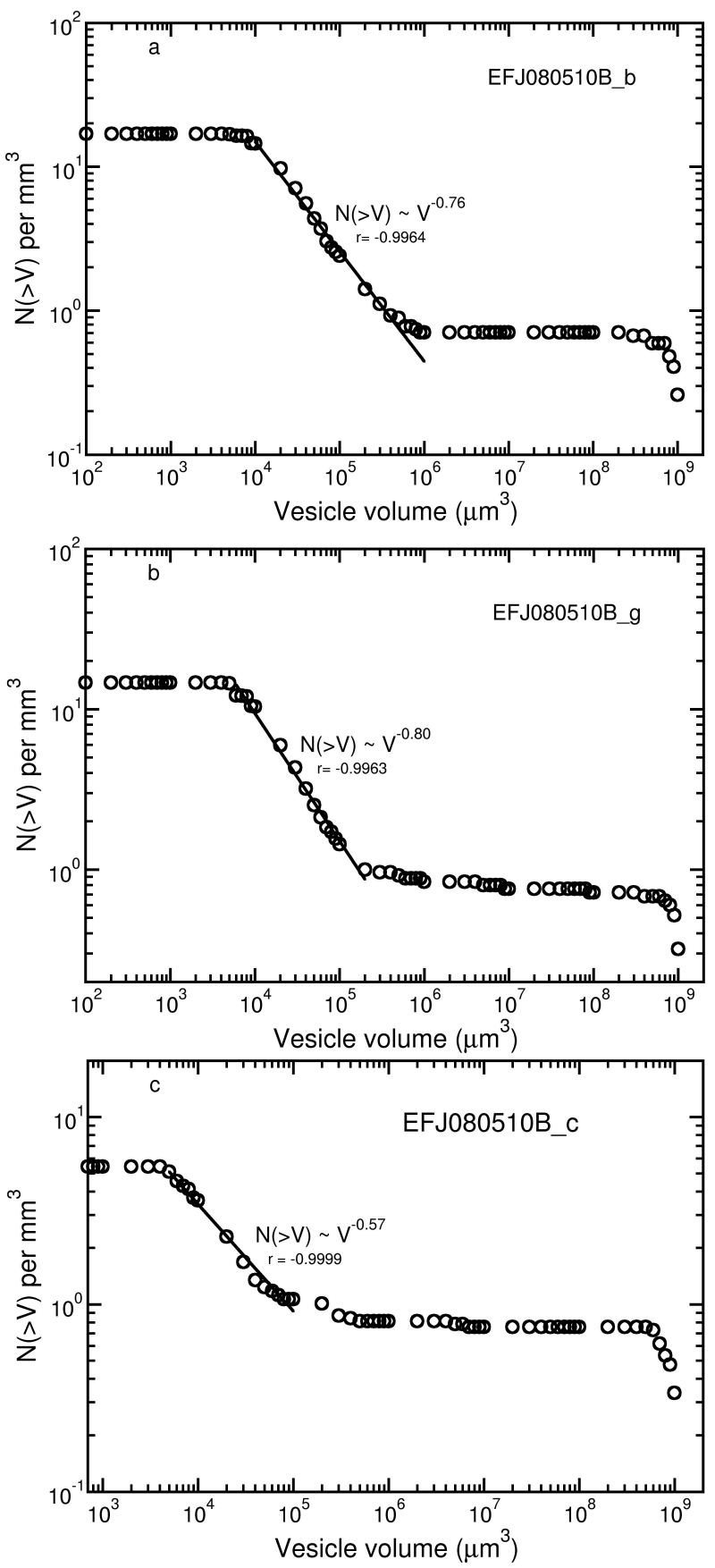

Fig. 2. Examples of cumulative vesicle size distributions in natural samples. (a) Natural sample EFJ050810B_b with a vesicularity of $65.5 \%$ and a VND of 17.0 per $\mathrm{mm}^{3}$. (b) Natural sample EFJ050810B_g with a vesicularity of $72.3 \%$ and a VND of 14.6 per $\mathrm{mm}^{3}$. (c) Natural sample EFJ050810B_c with a vesicularity of $77.6 \%$ and a VND of 5.4 per $\mathrm{mm}^{3}$. In each panel the open circles are the cumulative vesicle volume distributions per $\mathrm{mm}^{3}$, and the lines are power-law fits (using the software package Grace) to vesicle volumes between approximately $\sim 10^{4}$ and $10^{5} \mu \mathrm{m}^{3}$. All other natural cumulative vesicle size distributions can be found in the Supplement.
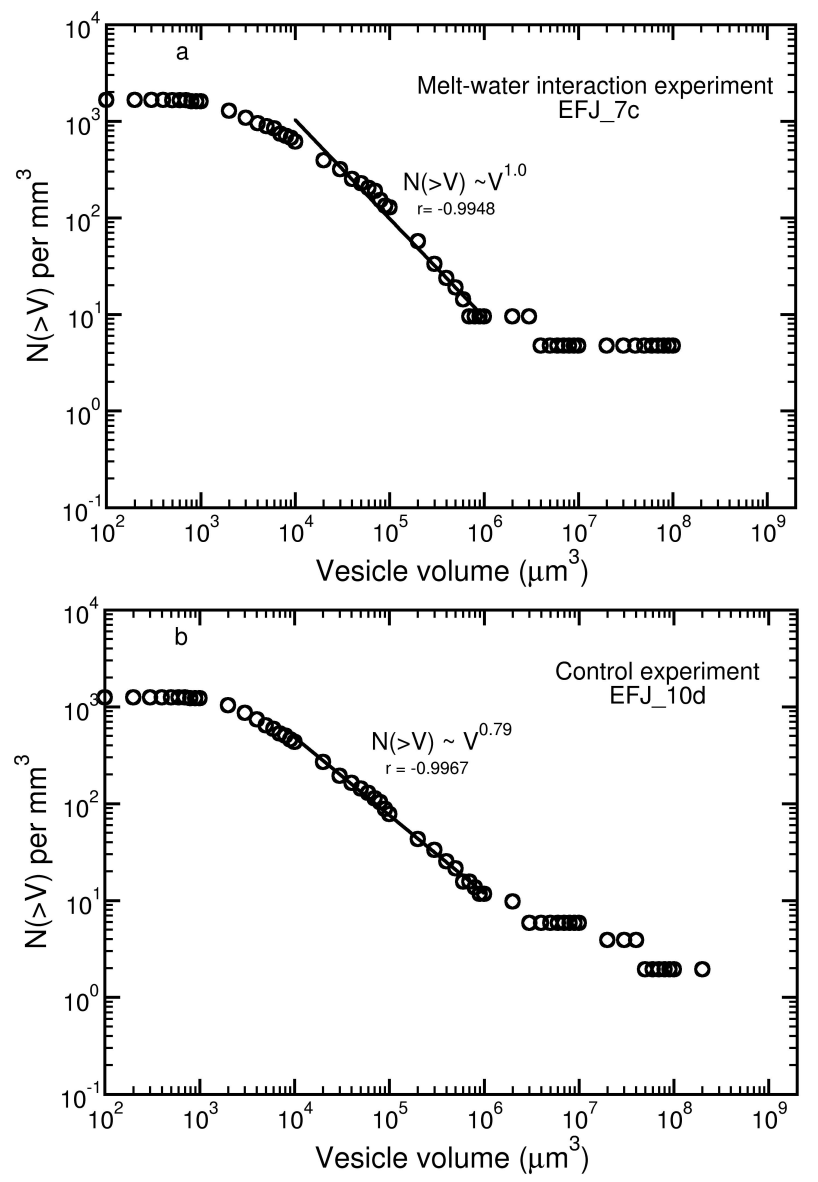

Fig. 3. Examples of cumulative vesicle size distributions in experimental run products. (a) Melt-water interaction experiment EFJ_7c with an initial water content of $2 \mathrm{wt} \%$, vesicularity of $54.5 \%$ and a VND of 1649 per $\mathrm{mm}^{3}$. (b) Control experiment EFJ_10d with an initial water content of $2.7 \mathrm{wt} \%$, vesicularity of $57.8 \%$ and a VND of 1246 per $\mathrm{mm}^{3}$. Note the similarity of the VSDs for the water inundation (a) and control (b) experiments, leading to the conclusion that the VSDs in the natural samples (Fig. 2) are controlled by the exsolution of magmatic volatiles and can be compared to measurements of VSDs at Stromboli volcano, Italy. In each panel the open circles in each figure are the cumulative vesicle volume distributions per $\mathrm{mm}^{3}$, and the lines are power-law fits (using the software package Grace) to vesicle volumes between approximately $\sim 10^{4}$ and $10^{5} \mu \mathrm{m}^{3}$. All other experimental cumulative vesicle size distributions can be found in the Supplement.

power-law exponents of $\sim 1$ (Polacci et al., 2008, 2009), whereas the paroxysmal explosions display power-law exponents of $\sim 1.5$ (Polacci et al., 2009). Two-dimensional measurements of the VSDs of basaltic scoria from the Fontana Plinian eruption (Costantini et al., 2010) at Masaya volcano, Nicaragua, and from the 122 BC Plinian eruption of Etna (Sable et al., 2006), Italy, also display VSD power exponents of $\sim 1.5$ when the measurements in the cited papers are converted from 2-D to 3-D. And, the VSDs of rhyodacitic pumices from the Plinian phase and pyroclastic flows 
of the Mt. Mazama eruption (Klug et al., 2002), Crater Lake, USA, follow a power law that has an exponent of $\sim 1.8$ when converted to 3-D. Furthermore, the laboratory experiments of Blower et al. (2001) of bubble growth and simulated volcanic eruptions using analog materials demonstrated that the power-law exponents describing the VSDs of their samples increased with increasing explosivity; they attributed the increase in the power-law exponent to multiple nucleation events. Although we recognize the need for further studies investigating the relationships between the power-law exponents of VSDs, magma composition, and eruption intensity, based upon these comparisons we hypothesize that in general the VSDs of low- to moderate-intensity eruptions at a volcano are characterized by 3-D power-law exponents near 1 , whereas the power-law exponents of VSDs of high-intensity eruptions are $\sim 1.5$ or higher. This relationship between the eruption intensity and the power-law exponent of the VSDs can thus be used as a key to the interpretation of natural scoria samples that have not suffered post-eruption modification such as turbulent mixing with water while above the glass transition.

\subsection{Eyjafjallajökull Phase II VSDs and eruption intensity}

The VSDs with power-law exponents of $\sim 0.8$ in Phase II Eyjafjallajökull scoria are close to the exponent of $\sim 1$ for VSDs in scoriae from typical Strombolian activity at Stromboli. This exponent and the correlation with Stromboli is consistent with the reduced intensity of Eyjafjallajökull eruptions during Phase II, with almost all ash columns only 3$4 \mathrm{~km}$ in height, compared to the preceding and subsequent phases (Phases I and III) that were characterized by more powerful explosive activity and eruption columns as high as $7 \mathrm{~km}$ (Gudmundsson et al., 2012).

The similar power-law exponents for samples from standard activity at Stromboli and those from Phase II of the 2010 Eyjafjallajökull eruption suggest the operation of similar mechanisms in the magma reservoirs and/or conduits, even though the volumes of individual explosions at Eyjafjallajökull were much larger (Gudmundsson et al., 2012). Burton et al. (2007) and Polacci et al. (2009) argued that during Stromboli's normal activity an uninterrupted pathway for gas ascent is created from the deeper to the shallower portion of the magmatic system, and it is able to sustain the persistent activity of the volcano. Phase II of the Eyjafjallajökull eruption thus appears similar to Stromboli's normal activity, because the explosions were supplied by a continuous inflow of mingled/mixed magma and gas from depth (Sigmarsson et al., 2011). This conclusion is further supported by the observation that scoriae from both Eyjafjallajökull Phase II eruption and standard Strombolian explosions contain large, interconnected vesicles; such large, spanning vesicles do not exist in pumice from Stromboli's paroxysmal explosions (Polacci et al., 2009), which have a deeper source (Allard, 2010) and display higher power-law exponents. The presence of these large, spanning vesicles enhances outgassing and reduces the possibility of generating significant overpressures leading to larger eruptions (Polacci et al., 2009).

The low VNDs of the natural samples imply postnucleation residence times of at least minutes, and possibly significantly longer prior to eruption. Bai et al. (2008) experimentally demonstrated significant changes in the VSDs and decreases in VNDs during their experiments with durations of minutes to tens of minutes. Based upon these measurements, Polacci et al. (2009) calculated that in the natural Stromboli system measurable changes in the VSDs and reductions in VNDs might require 100 to 1000 times longer than in experiments.

\section{Summary}

The power-law exponents of the Eyjafjallajökull Phase II eruption products investigated are slightly below 1 and similar to those of scoria formed at Stromboli volcano, Italy, during normal strombolian eruptions. Our experiments investigating magma-water interaction on VSDs found no significant effects; experimental samples all displayed power-law exponents similar to those seen in nature over the same vesicle volume range. We interpret the VSDs in the scoriae from the 2010 Eyjafjallajökull Phase II eruption to reflect gas-melt withdrawal by eruption from an open-conduit volcanic system supplied with deeper mingled/mixed magma. Our samples do not reveal any feature predictive of the increasing explosivity that characterized Phase III of the eruption, but they do indicate that there was no reason to expect the eruption intensity to decrease or the eruption to stop. Had we measured these samples at that time that would have been our conclusion. The findings of this study suggest that realtime monitoring of VSDs during a volcanic crisis using new, portable $\mu$-CT units (e.g., Tuniz et al., 2013) may rapidly provide valuable information to assess eruption intensity and to help policy makers in charge of mitigating volcanic hazards.

\section{Supplementary material related to this article is available online at http://www.solid-earth.net/4/373/ 2013/se-4-373-2013-supplement..pdf.}


Acknowledgements. Funding for this research was provided by an NSERC Discovery grant to D. R. B. and by Elettra proposal 20100027 to M. P. Portions of this work were performed at GeoSoilEnviroCARS (Sector 13), Advanced Photon Source (APS), Argonne National Laboratory. GeoSoilEnviroCARS is supported by the National Science Foundation - Earth Sciences (EAR-1128799) and Department of Energy - Geosciences (DEFG02-94ER14466). Use of the Advanced Photon Source was supported by the US Department of Energy, Office of Science, Office of Basic Energy Sciences, under contract no. DE-AC0206CH11357. We are very grateful to L. Mancini, who produced the rendering in Figure 1. P. A. and M. P. thank the VOLGASPEC project (ANR-06-CATT-012-01, France) for supporting fieldwork in Iceland. We thank the two anonymous reviewers and Thomas Shea, as well as Topical Editor Antonella Longo, for their comments and improvements to the paper.

Edited by: A. Longo

\section{References}

Abramoff, M. D., Magelhaes, P. J., and Ram, S. J.: Image processing with ImageJ, Biophot. Int., 11, 36-42, 2004.

Allard, P.: $\mathrm{A} \mathrm{CO}_{2}$-rich gas trigger of explosive paroxysms at Stromboli basaltic volcano, J. Volcanol. Geoth. Res., 189, 363-374, 2010.

Andronico, D., Corsaro, R. A., Cristaldi, A., and Polacci, M.: Characterizing high energy explosive eruptions at Stromboli volcano using multidisciplinary data: an example from the 9 January 2005 explosion, J. Volcanol. Geoth. Res., 176, 541-550, doi:10.1016/j.jvolgeores.2008.05.011, 2008.

Bai, L., Baker, D. R., and Rivers, M.: Experimental study of vesicle growth in Stromboli basalt melts at 1 atm, Earth Planet. Sc. Lett., 267, 533-547, doi:10.1016/j.epsl.2007.11.063, 2008

Bai, L., Baker, D. R., and Hill, R. J.: Permeability of vesicular Stromboli basaltic glass: lattice Boltzmann simulations and laboratory measurements, J. Geophys. Res., 115, B07201, doi:10.1029/2009JB007047, 2010

Bai, L., Baker, D. R., Polacci, M., and Hill, R. J.: In-situ degassing study on crystal-bearing Stromboli basaltic magmas: implications for Stromboli explosions, Geophys. Res. Lett., 38, L17309, doi:10.1029/2011GL048540, 2011.

Baker, D. R.: Piston-cylinder calibration at 400 to $500 \mathrm{MPa}$ : a comparison of using water solubility in albite melt and $\mathrm{NaCl}$ melting, Am. Mineral., 89, 1553-1556, 2004.

Baker, D. R. and Alletti, M.: Fluid saturation and volatile partitioning between melts and hydrous fluids in crustal magmatic systems: The contribution of experimental measurements and solubility models, Earth-Sci. Rev., 114, 298-324, 2012.

Baker, D. R., Mancini, L., Polacci, M., Higgins, M. D., Gualda, G. A. R., Hill, R. J., and Rivers, M. L.: An introduction to the application of X-ray microtomography to the threedimensional study of igneous rocks, Lithos, 148, 262-276, 2012.

Bertagnini, A., Coltelli, M., Landi, P., Pompilio, M., and Rosi, M.: Violent explosions yield new insights into dynamic of Stromboli volcano, EOS T. Am. Geophys. Un., 80, 633-636, doi:10.1029/99EO00415, 1999.
Blower, J.D., Keating, J.P. Mader, H.M., and Phillips, J.C.: Inferring volcanic degassing processes from vesicle size distributions. Geophys. Res. Lett., 28, 347-350, 2001.

Burton, M. R., Mader, H. M., and Polacci, M.: The role of gas percolation in quiescent degassing of persistently active volcanoes, Earth Planet. Sc. Lett., 264, 46-60, doi:10.1016/j.epsl.2007.08.028, 2007.

Cashman, K. V. and Mangan, M. T.: Physical aspects of magmatic degassing I I. Constraints on vesiculation processes from textural studies of eruptive products, Rev. Mineral., 30, 447-478, 1994.

Costantini, L., Houghton, B. F., and Bonadonna, C.: Constraints on eruption dynamics of basaltic explosive activity derived from chemical and microtextural study: the example of the Fontana Lapilli Plinian eruption, Nicaragua, J. Volcanol. Geoth. Res., 189, 207-224, doi:10.1016/j.jvolgeores.2009.11.008, 2010.

Gaonac'h, H., Lovejoy, S., Stix, J., and Scherzter, D. A.: Scaling growth model for vesicles in basaltic lava flows, Earth Planet. Sc. Lett., 139, 395-409, 1996.

Gudmundsson, M. T., Thordarson, T., Höskuldsson, A., Larsen, G., Björnsson, H., Prata, F. J., Oddsson, B., Magnússon, E., Högnadóttir, T., Petersen, G. N., Hayward, C. L., Stevenson, J. A., and Jónsdóttir, I.: Ash generation and distribution from the April-May 2010 eruption of Eyjafjallajökull, Iceland, Nature Scientific Reports, 2, 572, doi:10.1038/srep00572, 2012.

Hoskuldsson, A. and the Eyjafjallajökull eruption team: Eruption Dynamics of the 2010 Summit Eruption at the Eyjafjallajökull Volcano (Iceland): Magma Fragmentation, Tephra Stratigraphy and Transport, Geophys. Research Abstr., 13, EGU2011-14165, 2011, EGU General Assembly 2011, 2011.

Hurwitz, S. and Navon, O.: Bubble nucleation in rhyolitic melts: experiments at high pressure, temperature, and water content, Earth Planet. Sci. Lett., 22, 267-280, 1994

ICAO: Flight Safety and Volcanic Ash, ICAO Document 9974 available at: http://www.icao.int/publications/Documents/9974_ en.pdf, last access: 1 April 2013, 2012.

Ketcham, R. A.: Computational methods for quantitative analysis of three-dimensional features in geological specimens, Geosphere, 1, 32-41, doi:10.1130/GES00001.1, 2005

Klug, C., Cashman, K. V., and Bacon, C. R.: Structure and physical characteristics of pumice from the climactic eruption of Mount Mazama (Crater Lake), Oregon. Bull. Volcanol., 64, 486-501, 2002.

Lautze, N. C. and Houghton, B. F.: Linking variable explosion style and magma textures during 2002 at Stromboli Volcano, Italy, B. Volcanol., 69, 445-460, doi:10.1007/s00445-006-0086$1,2007$.

Mangan, M. T. and Cashman, K. V.: The structure of basaltic scoria and reticulite and inferences for vesiculation, foam formation, and fragmentation in lava fountains, J. Volcanol. Geoth. Res., 73, $1-18,1996$.

Métrich, N., Bertagnini, A., Landi, P., and Rosi, M.: Triggering mechanism at the origin of paroxysms at Stromboli (Aeolian Archipelago, Italy): the 5 April 2003 eruption, Geophys. Res. Lett., 32, L10305, doi:10.1029/2004GL022257, 2005.

Polacci, M., Baker, D. R., Bai, L., and Mancini, L.: Large vesicles record pathways of degassing in basaltic magmas, B. Volcanol., 70, 1023-1029, 2008

Polacci, M., Baker, D. R., Mancini, L., Favretto, S., and Hill, R. J.: Vesiculation in magmas from Stromboli and implications for nor- 
mal Strombolian activity and paroxysmal explosions in basaltic systems, J. Geophys. Res., B1, 114, doi:10.1029/2008JB005672, 2009.

Polacci, M., Mancini, L., and Baker, D. R.: The contribution of synchrotron X-ray computed microtomography to understanding volcanic processes, J. Synchrotron Radiat., 17, 215-221, doi:10.1107/S0909049509048225, 2010.

Rivers, M.: Tutorial Introduction to X-ray Computed Microtomography Data Processing, available at: http://www.mcs.anl. gov/research/projects/X-ray-cmt/rivers/tutorial.html, last access: 30 April 2012, University of Chicago, 1998.

Sable, J. E., Houghton, B. F., Del Carlo, P., and Coltelli, M.: Changing conditions of magma ascent and fragmentation during the Etna 122 BC basaltic Plinian eruption: evidence from clast microtextures, J. Volcanol. Geoth. Res., 158, 333-354, 2006.

Sigmarsson, O., Vlastelic, I., Andreasen, R., Bindeman, I., Devidal, J.-L., Moune, S., Keiding, J. K., Larsen, G., Höskuldsson, A., and Thordarson, Th.: Remobilization of silicic intrusion by mafic magmas during the 2010 Eyjafjallajökull eruption, Solid Earth, 2, 271-281, 2011.
Sigmundsson, F., Hreinsdottir, S., Hooper, A., Arnadottir, T., Pedersen, R., Roberts, M. J., Oskarsson, N., Auriac, A., Decriem, J., Eirnarsson, P., Geirsson, H., Hensch, M., Ofeigsson, B. F., Sturkell, E., Sveinbjornsson, H., and Feigl, K. L.: Intrusion triggering of the 2010 Eyjafjallajökull explosive eruption, Nature, 468, 426-30, doi:10.1038/nature09558, 2010.

Thomas, H. E. and Prata, A. J.: Sulphur dioxide as a volcanic ash proxy during the April-May 2010 eruption of Eyjafjallajökull Volcano, Iceland, Atmos. Chem. Phys., 11, 6871-6880, doi:10.5194/acp-11-6871-2011, 2011.

Tuniz, C., Bernardini, F., Cicuttin, A., Crespo, M. L., Dreossi, D., Gianoncelli, A., Mancini, L., Mendoza Cuevas, A., Sodini, N., Tromba, G., Zanini, F., and Zanolli, C.: The ICTP-Elettra X-ray laboratory for cultural heritage and archaeology, Nucl. Instrum. Meth. A., 711, 106-110, doi:10.1016/j.nima.2013.01.046, 2013. 